\title{
Social capital in the creation of Al perception
}

\author{
Yoji Inaba ${ }^{1} \cdot$ Kazunari Togawa
}

Received: 3 December 2019 / Accepted: 5 March 2020 / Published online: 26 March 2020

(c) The Author(s) 2020

\begin{abstract}
Numerous studies over the past 30 years have examined the relationship between social capital (SC) and information and communication technology (ICT). However, few studies have examined the association between artificial intelligence (AI) and SC. This study addresses this gap using a Web survey $(n=5000)$ carried out in the Tokyo metropolitan area in Japan in 2018. The survey included questions on ICT literacy and SC (networks, trust, norms of reciprocity), as well as questions on perceptions of AI including its impact on society. Based on the survey, we extracted four SC factors: cognitive SC, and three forms of structural SC, namely contacts with others, group participations, and SC at work place. We found a statistically significant positive association between $\mathrm{SC}$ and positive perceptions of AI through ITC literacy. SC is indirectly associated with AI perception by enhancing ICT literacy, and then ICT literacy enhances AI perception. This indirect effect seems to be mainly caused by two types of structural SC: SC through group participations and SC at work place. Besides this indirect effect, SC has direct effect on AI perception. Cognitive SC has direct positive association with AI perception, whereas structural SC in the form of contacts with others was negatively associated with AI perception. Thus, structural SC has an ambivalent effect on AI perception. Structural SC through group participation as well as SC at work place may work for the positive perceptions of AI through ICT literacy, while those with higher level of contacts with others tend to be cautious toward AI. Both cognitive SC and structural SC assume important roles for the smooth transition into the AI era. Policy makers should be aware of the difference in the way each of these SC forms affects AI perception. SC seems to have mainly promotional impact on the AI perception. However, the precautionary function of SC should not be put on the back burner for the sound social acceptance of AI. In any case, SC assumes an important role in the creation of AI perception.
\end{abstract}

Keywords Social capital $\cdot$ ICT $\cdot$ AI $\cdot$ Networks

Communicated by Takahiro Hoshino.

The title is inspired by Coleman (1988).

Extended author information available on the last page of the article 


\section{Introduction}

Although we are moving into an era where Artificial Intelligence (AI) is fast becoming the norm, many of us are still at a loss about what AI can and will bring to society at least in Japan. This is clearly illustrated by the results of a survey $(n=5000)$ we conducted in 2018, which asked respondents about the impact of AI on society. ${ }^{1}$ Our survey focused on seven items, namely whether AI will make us happier, strengthen or weaken human relations, enhance or control our lives, free us from hard work or make us poor, enhance or deprive us of our creativity, make our society crime free or place it under heavier surveillance, and decrease or increase economic inequality. To our surprise, most respondents $(n=5000)$ offered negative views on all seven items except for one, namely the availability of information. Four out of five respondents expected economic inequality to increase. In light of these results, it seems important to mitigate these pessimistic views by enhancing the social acceptance of AI prior to its implementation in society. This paper aims to address this issue by examining the association between AI perception and social capital (SC) through the use of information and communications technology (ICT) as an intermediary. SC can be affected by AI and is also a prerequisite for the social acceptance of AI. This study used the abovementioned survey $(n=5000)$ that was carried out in the Tokyo metropolitan area in Japan in 2018. The survey asked questions on ICT literacy and SC (networks, trust, and norms of reciprocity), and on perceptions of $\mathrm{AI}$ among the respondents.

Definitions of SC differ among researchers (Bourdieu 1986; Coleman 1987, 1988; Burt 1992; Putnam 1993, 2000; Woolcock 1998; OECD 2001; Lin 2001; Bowls and Gintis 2002; Ostrom 1999; Ostrom and Ahn 2009). For this paper, we followed Inaba (2005), who defined SC as "trust, norms of reciprocity, and networks with externalities through human minds." Since externalities can be negative, this definition includes the negative aspects of SC as well. Networks are often called structural $\mathrm{SC}$, trust and norms are called cognitive SC, SC that connects people with different backgrounds is called bridging SC, and SC that connects people with the same background is classified as bonding SC.

This study defines AI in line with the definition provided by the Japanese Society for Artificial Intelligence (Ishizuka et al. 2017, p. 2): "AI is computer systems with intelligent capabilities equivalent to human beings to infer, recognize and judge."

The rest of this paper is organized as follows. We begin with a survey of previous studies on SC and ICT to identify our research strategies. Then, we implement the research strategies using the data collected through our survey. First, factor analyses are conducted to identify the basic factors pertaining to SC, ICT literacy, and perceptions of AI. Second, we analyze the association between SC and AI perception via ICT literacy. Then, we proceed to analyze AI perception using SC and ICT literacy as explanatory variables.

${ }^{1}$ The details of the survey are described in Sect. 3.1. 
Table 1 Three waves of preceding studies

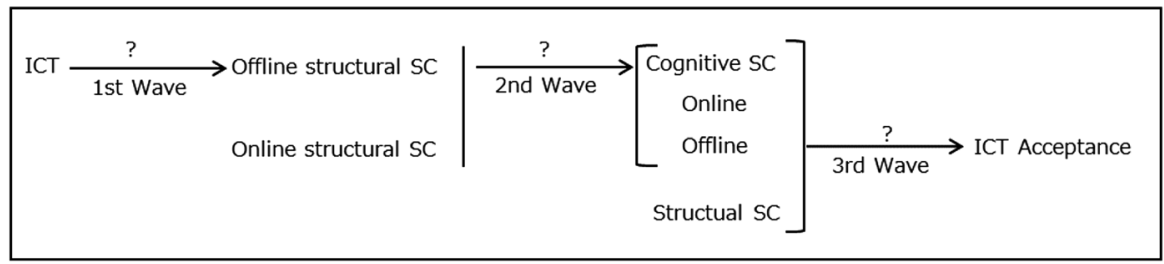

\section{Previous studies and research questions}

There have been numerous studies on the relationship between SC and the use of ICT such as email, social networking services (SNSs), blogs, bulletin boards, knowledge collaborations, and video-sharing systems (Putnam 2000; Wellman et al. 2001; Yang et al. 2009; Ahmed 2018; Suda 2018). As seen in Table 1, these studies appear to have occurred in three waves, reflecting the increasing use of and progress in ICT. The first wave focused on the impact of ICT on the structural side of offline SC, namely activities related to the networks in the real world. When the second wave began in the 2000s, research shifted its focus onto the impact of ICT on the cognitive side of both online and offline SC including the norms of reciprocity and trust, both in the virtual and the real worlds. Over the past decade, the third wave seems to have dealt with causality from SC to the penetration of ICT rather than vice versa.

\subsection{Previous studies}

\subsubsection{First wave}

The first wave, which continued until the middle of the 2000s, focused mainly on the impact of ICT on the structural side (networks) of SC offline. It focused on whether ICT use complemented the existing offline structural SC or functioned as a substitute for it.

Wellman et al. (2001) examined the impact of the Internet on structural SC based on the data of 39, 211 North American adult participants of a survey conducted by the National Geographic Society in 1998. They found that the interactions online supplemented both face-to-face and telephonic communications without altering the extent of their occurrence. They could not find an association between Internet use and structural SC in the forms of face-to-face and telephonic communications except for the case in which heavy Internet use was associated with increased participation in voluntary organizations and politics. Their findings indicated partially complementing effects of ICT on offline structural SC.

Nie and Erbring (2002) surveyed a randomly selected sample of 4113 individuals in the US in 1999 and found that Internet use was negatively associated with the amount of time the respondents spent with their family and friends, and the time 
they spent on events outside home. Thus, they concluded that Internet use may have had a negative impact on offline structural SC.

Norris (2003) investigated the following research questions in relation to the impact of the Internet on offline structural SC.

"How do traditional communities overlap and interact with virtual social networks? Can online communities become substitutes for traditional forms of collegiality and social interaction based on traditional face-to-face contact in families, firms and local communities?" (Norris 2003, p 2).

Norris addressed these research questions in an empirical study using data from the Pew Internet and America Life Survey conducted in 2001, and found that "online contact did bring together like-minded souls, who share particular beliefs, hobbies or interests...Equally importantly, the joining of many different types of online groups was also perceived to broaden social contacts" (Ibid.). This means that online contact complemented existing offline bonding SC, and also functioned as a substitute for existing offline networks by expanding and bridging $\mathrm{SC}$ through the Internet. Norris found that the Internet had a slightly stronger impact on offline bonding SC than on offline bridging SC.

Kobayashi and Ikeda (2006) also explored the possibility that online SC would have a positive effect on offline structural SC. They conducted two web-based surveys using players of the MMORPG "LINEAGE," which involved multiple strangers $\left(n^{\mathrm{W} 1}=1801, n^{\mathrm{W} 2}=1365\right)$. They found that after controlling for gender, age, educational attainment, household revenue, employment, and disposal time of respondents as well as offline SC, online reciprocity within the LINEAGE community promoted social participation in offline communities. This supports the finding that ICT functions as a complement to existing structural SC in the offline world.

Some studies shed light on personality. Ellison et al. (2007) suggested that Facebook may provide greater benefits for users experiencing low self-esteem and low life satisfaction by helping them bridge their SC. Their conclusion was shared by Terashima and Miura (2013) in which the authors found that SNS usage by those with low sociability were more likely to affect their online bridging SC. Kim et al. (2013) examined how social media use affected individuals' discussion network heterogeneity and their level of civic engagement. Their results supported the notion that the use of social media contributed to the heterogeneity of discussion networks and activities in civic life. They also found that the contributing role of social media in increasing network heterogeneity and civic engagement was greater for introverted and less open individuals.

The question whether ICT use could complement or substitute structural SC has remained valid, and subsequent empirical studies have approached it by expanding the scope of their studies into many other situations including Ryan (2010) who found that ICT use increases SC in healthcare; Zhong (2014) who found that SNS had a positive impact in enhancing online bridging and bonding SC and had a limited impact on offline bonding SC; Bauernschuster et al. (2014) who found that the Internet had a positive impact on SC index that was mainly composed of structural SC based on nationwide data from Germany; Li and Chen (2014) who found that SNS functioned as both a complement and/or a substitute depending on the location 
of ties; and Nolan et al. (2015) who concluded that SNS enhances the social ties of "adolescent mothers," and thus complements existing SC. Most studies have indicated that ICT use enhances online structural SC and has a somewhat smaller impact on offline SC.

Some researchers extended the scope of their studies to examine the negative aspect of SC in ICT use. Habuchi (2005, p. 167) studied mobile technology and observed that "a zone of intimacy in which people can continuously maintain their relationships with others who they have already encountered without being restricted by geography and time." She defined "the small enclaves of like-minded clusters" as a tele-cocoon. Gergen (2008), Ling (2008), and Campbell and Kwak (2012) followed suit with a natural extension of the concept of tele-cocoons together with their empirical findings, all of which brought about the tele-cocooning hypothesis, which Kobayashi and Boase (2014, p. 682) described thus: "if texting facilitates contact with close friends and family exclusively, and if it reduces heterogeneous encounters, it can have a cocooning effect by focusing one's attention on existing close relation at the expense of reaching out to new people." The hypothesis suggests a tradeoff between offline bonding SC at the price of offline bridging SC through the use of ICT.

Despite the large volume of previous empirical work, the basic research question on whether ICT use complemented existing offline structural SC or functioned as a substitute for it has not been fully answered yet. There are two schools of thought as described by Wellman et al. (2001), one each for the substitute and complement hypotheses. Both hypotheses are plausible enough. The results of preceding empirical works have been mixed. However, at least, as originally suggested by Putnam (2000) and Norris (2003), and the cocooning effect, ICT use seems to bring about a trade-off by somewhat enhancing offline bonding SC at the expense of offline bridging SC. SNSs may also have a positive impact of enhancing one's bridging SC in the cases of those with somewhat reserved personalities.

\subsubsection{Second wave}

The second wave of studies, which commenced in the mid-2000s, expanded the scope of the literature to include cognitive aspects (trust and norms) of offline SC, with academic interest shifting toward the relationship between the online cognitive SC created by ICT and offline cognitive SC. For instance, Miyata (2005a, b, c) and Miyata et al. (2005) conducted comprehensive studies on the impact of the Internet on SC using panel datasets based on three panel surveys in Yamanashi Prefecture in Japan between 2002 and $2005\left(n^{\mathrm{W} 1}=1002, n^{\mathrm{W} 2}=646, n^{\mathrm{W} 3}=432\right)$. She found that continuous participation in online communities could diminish cognitive SC in the form of generalized trust, or at least fail to enhance the generalized trust of participants in online communities. Conversely, emails sent from cell-phones had an insignificant impact on online generalized trust, while emails sent from PCs increased online generalized trust. Miyata also analyzed the changes that occurred among the three surveys and found a spillover effect of online generalized trust to offline generalized trust through an increase in generalized reciprocity. Thus, ICT was found to affect offline cognitive SC. 
However, there are more pessimistic views on the impact of ICT on society as a whole. Tsuji (2014) analyzed the impact of mobile media on cognitive SC (generalized trust and the norms of reciprocity) using the results of their mobile media surveys conducted in $2001(n=1876)$ and in $2011(n=1452)$. He found no association between the norms of reciprocity and ICT use. Although he found a partial association between Internet use through PCs and online generalized trust, no association was observed between ICT use and offline generalized trust.

Salahuddin et al. (2016) analyzed the effects of the Internet and real GDP per capita on the creation of trust in Australia between 1985 and 2013 and obtained mixed results. They found that Internet use reduced SC in the long run, but enhanced it slightly in the short run.

Although there is some uncertainty around the impact of ICT use on cognitive $\mathrm{SC}$, especially generalized trust (trust in society as a whole), it generally seems to enhance online cognitive SC in small networks such as university classes. Lu et al. (2013) analyzed data from online classes and found that ICT use in the form of online learning facilitates SC formation, mostly in terms of trust, collective action, and cooperation among class members.

\subsubsection{Third wave}

The third wave commenced in around 2010, reflecting the diffusion of smart phones. Studies during the third wave analyzed the penetration of ICT into daily life by focusing on the impact of SC on society's acceptance of ICT, rather than vice versa.

Penard and Poussing (2010) analyzed data from a survey of 1554 individuals aged between 16 and 74 years in Luxembourg in 2002 to identify the relationship between ICT and SC after taking opportunity costs in terms of time of IT users into account. Although their main research questions are the impact of ICT on SC, they also found that individuals with a large stock of SC are more likely to use the Internet to maintain their existing SC. A high level of trust in others increases the probability of maintaining social capital through the Internet. In addition, they also found that those involved in many associations used the Internet more intensively. That is, people with a large stock of SC are likely to increase their use of ICT to maintain their existing offline SC. A rich SC environment fosters Internet use to maintain one's SC. That is, high SC brings about a complementarity between ICT and SC.

Kuo et al. (2013) examined the case of an ICT learning program for digital-illiterate and middle-aged females $(n=133)$ in Taiwan. They found that female ICT beginners who valued social connections and relationships with their classmates and friends were encouraged to gain ICT skills because they got to learn and care for each other. The cooperation lasted after the program ended, and thus extended their personal networks in cyberspace.

Naranjo-Zolotov et al. (2019) examined the impact of SC on ICT use (focusing on the use of electronic participatory platforms, abbreviated to "e-participation") using data from a sample of 200 people collected in Portugal in 2016. They hypothesized that a high level of SC would have a positive effect on either intended or actual e-participation. They used "trust in local government," "feeling of identification as a citizen within the community," "social interaction between members of 
Table 2 Three waves preceding studies and the scope of the present paper

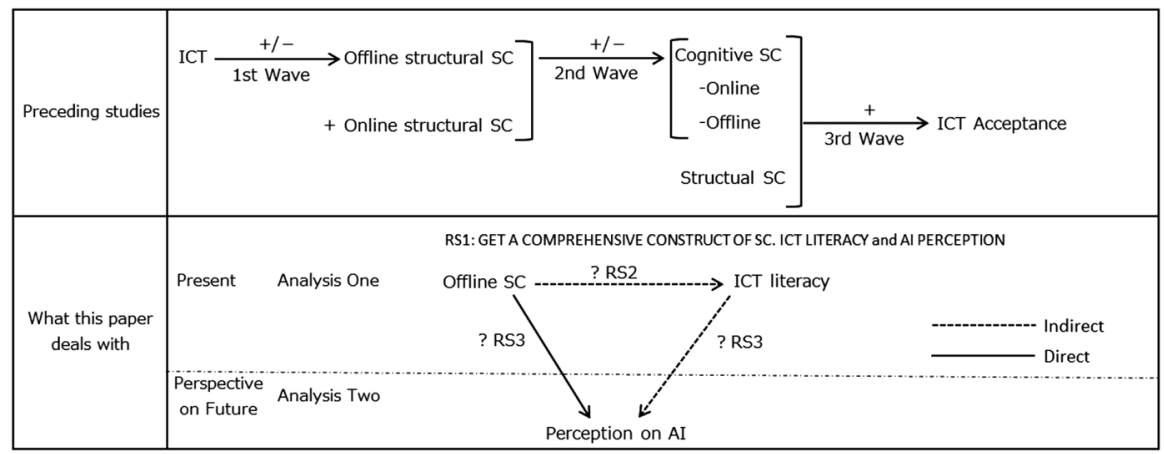

a given community," and "reciprocity between members of the community" as SC variables. Of these, "identification" and "interaction" were significantly associated with e-participation, while "reciprocity" and "trust in local government" were not. Therefore, the impact of SC on ICT use in the form of e-participation was more likely to be affected by structural aspects of SC rather than cognitive aspects of SC such as trust and reciprocity.

Although ICT use can enhance online structural SC, its impact on offline structural SC depends on the situation and the content of the ICT. Until the mid-2000s, the introduction of ICT functioned as a complement to and/or a substitute for existing offline SC (first wave). Researchers also found that online structural SC created by ICT mainly enhanced offline cognitive SC of relatively small groups. However, the results seem to be mixed for large populations (second wave). Currently, offline SC backed up by online structural SC generally seems to have a positive impact on ICT acceptance in society.

\subsection{Research strategies (RS)}

In light of the trends in previous studies, this study adopts SEM. We assume that the three principle variables in this study, namely SC, ICT literacy, and AI perception are different in terms of tense. SC and ICT literacy belong to the present, while AI perception is related to the future. As shown in Table 2, the association between AI perception and SC/ICT literacy is different from that between SC and ICT literacy. The former deals with the association between a variable on future projections (AI perception) and variables related to the present (SC and ICT literacy); whereas, the latter only deals with the associations between variables in the present.

RS1 Grasp the comprehensive constructs of SC, ICT literacy, and AI perception.

Both SC and ICT literacy are multifaceted concepts. However, most preceding studies have focused on the impact of one particular type of ICT such as the use of SNS. This lack of comprehensive analysis is also evident in relation to previous studies on SC that have mostly been based on partial aspects of SC such as networks, trust, and norms. Therefore, in the first place, we grasp the 
comprehensive constructs of both SC and ICT literacy. We also try to get a comprehensive construct of AI perception.

$R S 2$ Confirm the association between SC and ICT literacy.

Studies in third wave have suggested mostly affirmative associations between SC and ICT literacy with the partial element of SC. The second step of our strategy is to confirm the association between SC and ICT literacy using more comprehensive constructs of SC and ICT literacy as obtained by RS1. Although AI covers areas that are wider than those covered by ICT, ICT is a gateway to the AI era as many devices and software used in AI are based on ICT. ICT provides an interface between $\mathrm{AI}$ and humans, and thus functions as an intermediary between SC and AI perception. RS2 is, thus, a step to find out the indirect impacts of SC on AI perception through ICT literacy. In other words, we test the validity of the contents, namely factors obtained through the explanatory analyses using the results of the preceding studies mainly in the above-mentioned third wave studies.

RS3 Find out the association between AI perception and ICT literacy/SC.

$\mathrm{SC}$ can have a direct impact on AI perception as well. Trust and norms of reciprocity on society as a whole, which are important elements of SC, may alleviate pessimistic perspectives on AI. Networks can either promote or alleviate the formation of pessimistic AI perception. Homophily caused by bonding SC tends to create strong ties among the members of a group and may promote exclusive activities toward non-members. In this case, SC can lead to pessimistic views. On the other hand, heterophily derived from bridging SC may provide people with opportunities to come in contact with various kinds of people which may make them more generous toward new technologies including AI. RS3 tries to find this direct impact between SC and AI perception and that between ICT literacy and AI perception.

$R S 4$ Draw policy implications.

What are the policy implications of the enhancement of the social acceptance of AI?

\section{Materials and methods}

\subsection{Data}

The dataset used in this study was obtained from a web-based survey conducted between September 4 and 10, 2018. The survey sample included residents aged between 20 and 69 years living in the Tokyo metropolitan area including Tokyo, Kanagawa, Chiba, and Saitama prefectures. Responses were received from 5000 people, as seen in Table 3.

The questionnaire included items on the following topics.

\section{ICT literacy.}


Table 3 Survey on the impact of AI: descriptive statistics

\begin{tabular}{|c|c|c|c|c|}
\hline & $N$ & $\%$ & Std. & Range \\
\hline \multicolumn{5}{|l|}{ Sex } \\
\hline Male & 2502 & 50.0 & & \\
\hline Female & 2498 & 50.0 & & \\
\hline Age (years) & 5000 & Mean 44.80 & 13.9 & $20-69$ \\
\hline \multicolumn{5}{|l|}{ Educational attainment } \\
\hline Junior high school & 91 & 1.8 & & \\
\hline Senior high school & 1162 & 23.2 & & \\
\hline Junior college/technical college/vocational school & 1073 & 21.5 & & \\
\hline University & 2374 & 47.5 & Mode & \\
\hline Graduate school & 292 & 5.8 & & \\
\hline Other & 8 & 0.2 & & \\
\hline \multicolumn{5}{|l|}{ Annual income (million yen) } \\
\hline None & 67 & 1.3 & & \\
\hline$<2.00$ & 311 & 6.2 & & \\
\hline $2.00-3.99$ & 764 & 15.3 & & \\
\hline $4.00-5.99$ & 946 & 18.9 & & \\
\hline $6.00-7.99$ & 637 & 12.7 & & \\
\hline $8.00-9.99$ & 497 & 9.9 & & \\
\hline $10.00-14.99$ & 422 & 8.4 & & \\
\hline$\geqq 15.00$ & 185 & 3.7 & & \\
\hline Do not know/no answer & 1171 & 23.4 & Mode & \\
\hline \multicolumn{5}{|l|}{ Dwellings } \\
\hline Detached house & 2040 & 40.8 & Mode & \\
\hline Condominium & 1158 & 23.2 & & \\
\hline Public housing & 142 & 2.8 & & \\
\hline Municipal housing & 43 & 0.9 & & \\
\hline Apartment & 1431 & 28.6 & & \\
\hline Company house/dormitory/civil servants housing & 117 & 2.3 & & \\
\hline Other & 69 & 1.4 & & \\
\hline \multicolumn{5}{|l|}{ Occupation } \\
\hline Professional & 649 & 19.8 & & \\
\hline Administrative and managerial & 389 & 11.9 & & \\
\hline Clerical & 1176 & 35.9 & Mode & \\
\hline Sales & 266 & 8.1 & & \\
\hline Service & 459 & 14.0 & & \\
\hline Manufacturing process/labor/security & 318 & 9.7 & & \\
\hline Agriculture/forestry/fishery & 15 & 0.5 & & \\
\hline \multicolumn{5}{|l|}{ Employment type } \\
\hline Temporary employee/part-time/albeit & 664 & 20.3 & & \\
\hline Temporary/contractor/contract work/commissioned work & 361 & 11.0 & & \\
\hline Regular staff including public servants and teachers & 1801 & 55.0 & Mode & \\
\hline Self-employed worker or family worker & 297 & 9.1 & & \\
\hline
\end{tabular}


Table 3 (continued)

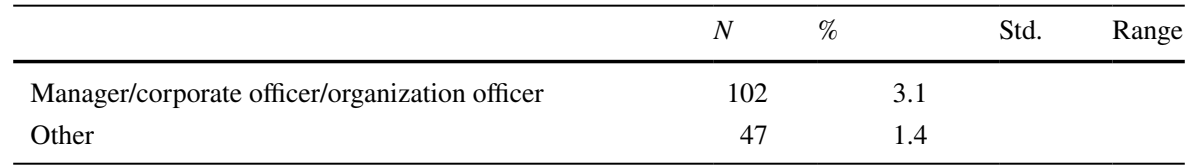

As seen in Table 4, we included 36 questions on ICT literacy. We had:

- 8 questions on access to ICT devices and PC (yes or no),

- 14 questions on the frequency of use of ICT devices and web services, measured using a three-point Likert scale, ${ }^{2}$

- 8 questions on the capability of PC and software and web usage, measured using a four-point Likert scale, and

- 6 questions on experience using AI-related equipment, measured using a threepoint Likert scale.

\section{2. $\mathrm{SC}$}

As seen in Table 5, we asked 12 questions on SC. We had:

- 8 questions related to structural SC including group participation, and relationships with neighbors, family members, relatives, friends and acquaintances, and colleagues, measured using four- to seven-point Likert scales, and

- 4 questions related to cognitive SC including trust and norms of reciprocity, measured using a four-point Likert scale.

\section{Perceptions of AI}

As seen in Table 6, there were 30 questions on respondents' perceptions of AI: the social influence of AI, whether the respondents have affirmative or negative opinions on AI in specific situations, the respondent's personal intention to use AI in specific applications, and the respondent's choices between AI and human beings in seven applications. We had:

- 7 questions on the social influence of AI, 1 measured using a five-point Likert scale and 6 measured using a four-point Likert scale from the perspective of whether AI will make our society better or worse,

- 8 questions on opinions on personal preference(the pros and cons of AI use in specific situations) of the respondents, measured using a five-point Likert scale,

- 8 questions on impact on society of AI use in 8 specific situations, measured using a five-point Likert scale, and

\footnotetext{
${ }^{2}$ Refer to Inaba and Yoshino (2016) for the appropriateness of the use of the Likert scale.
} 


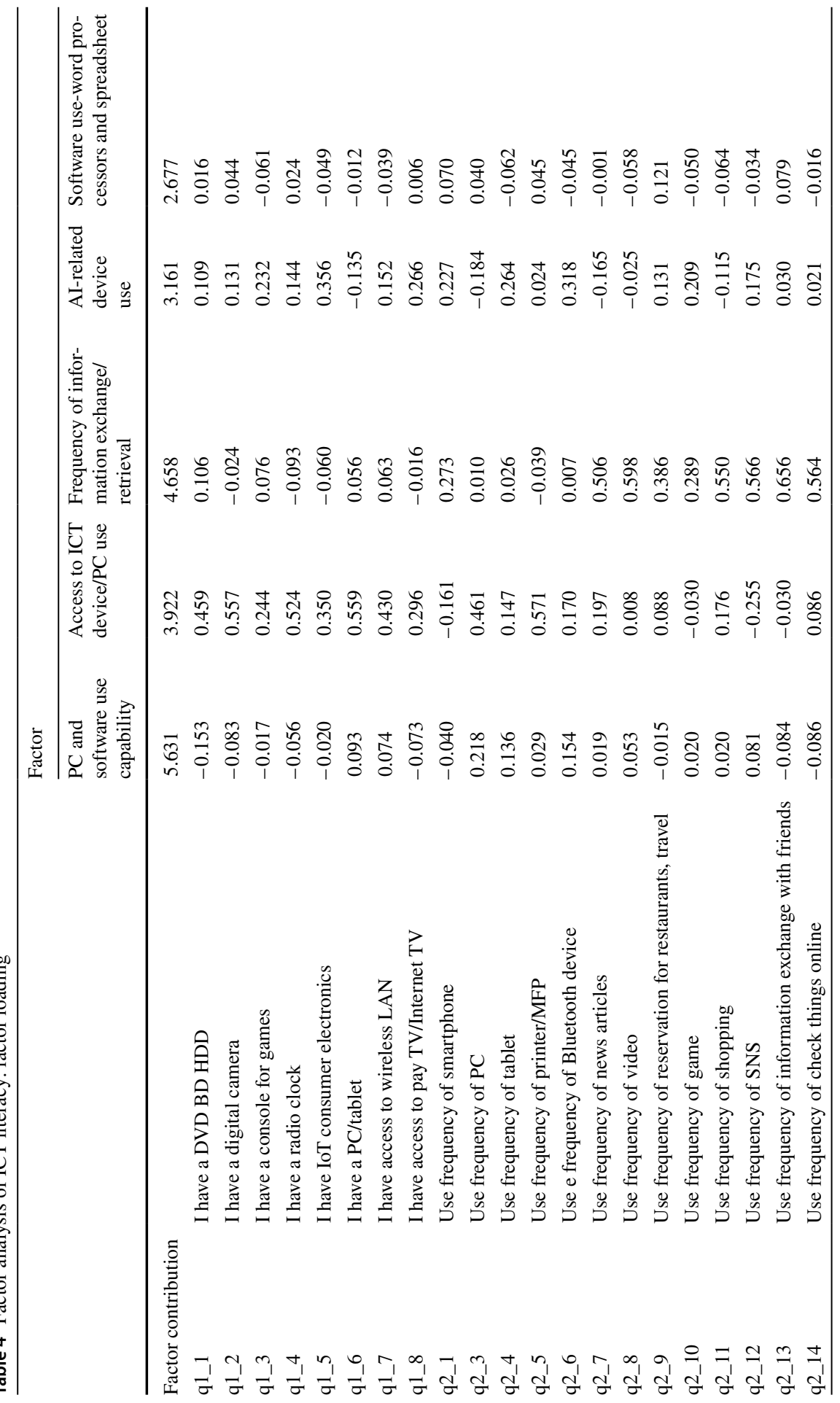




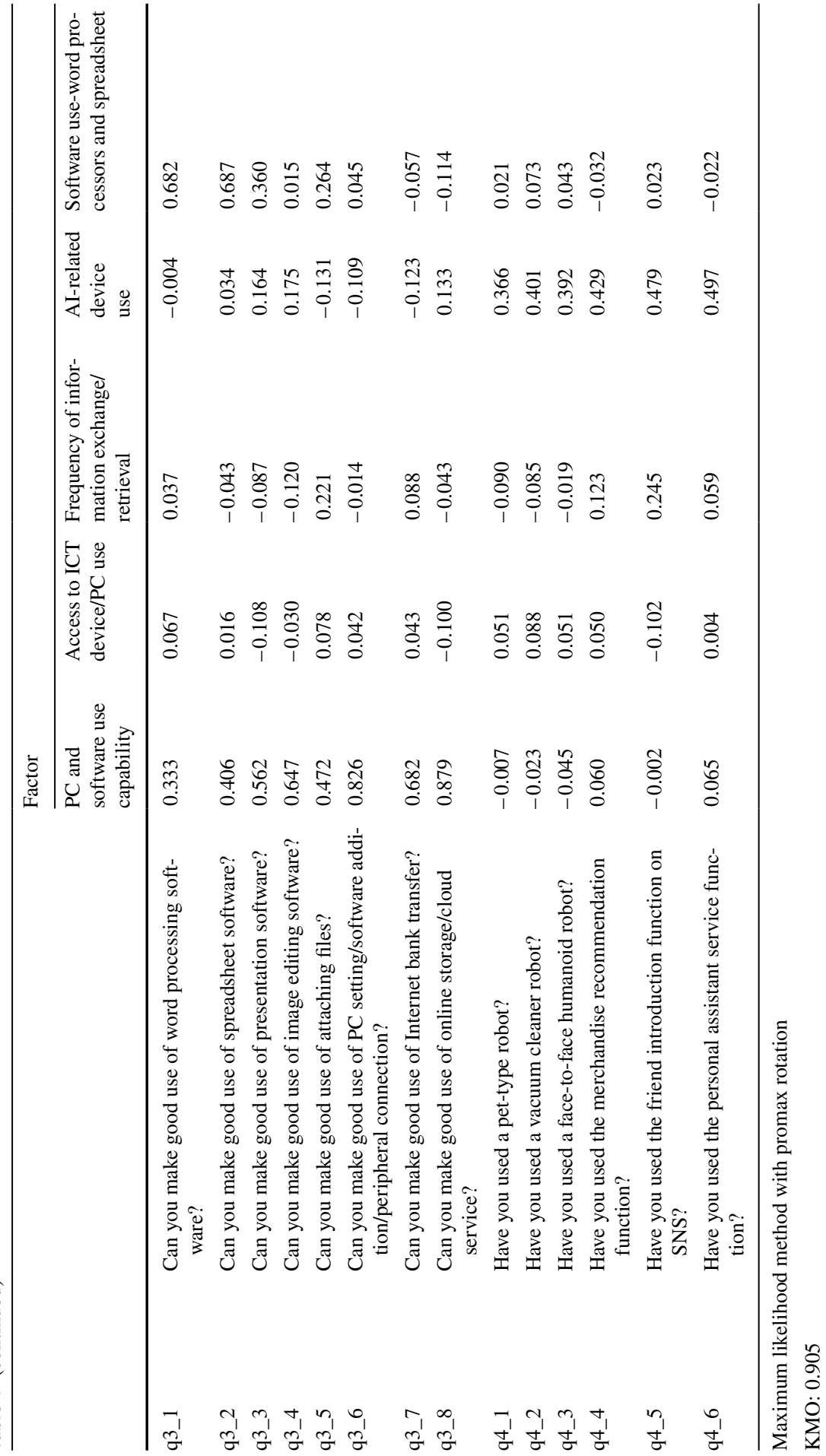




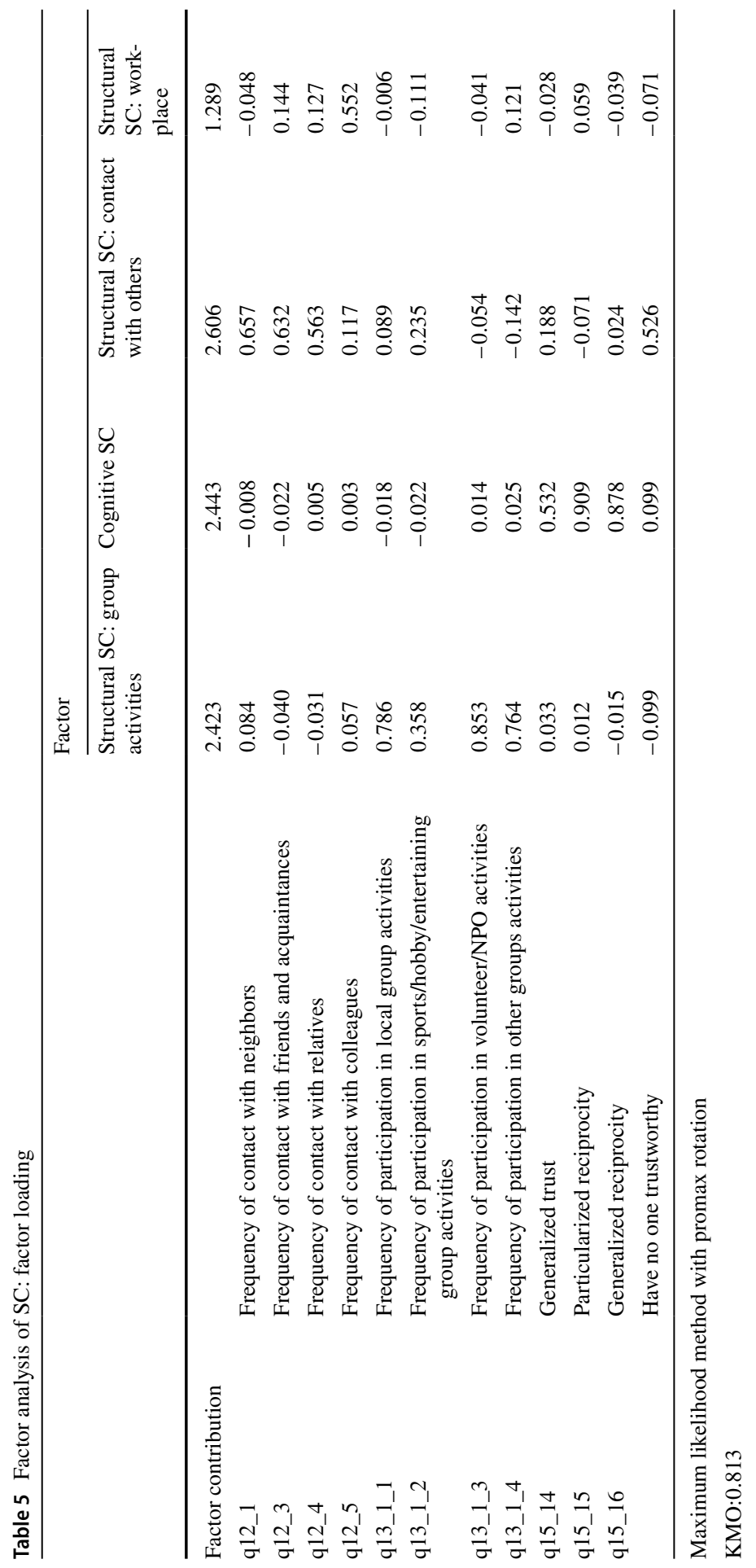




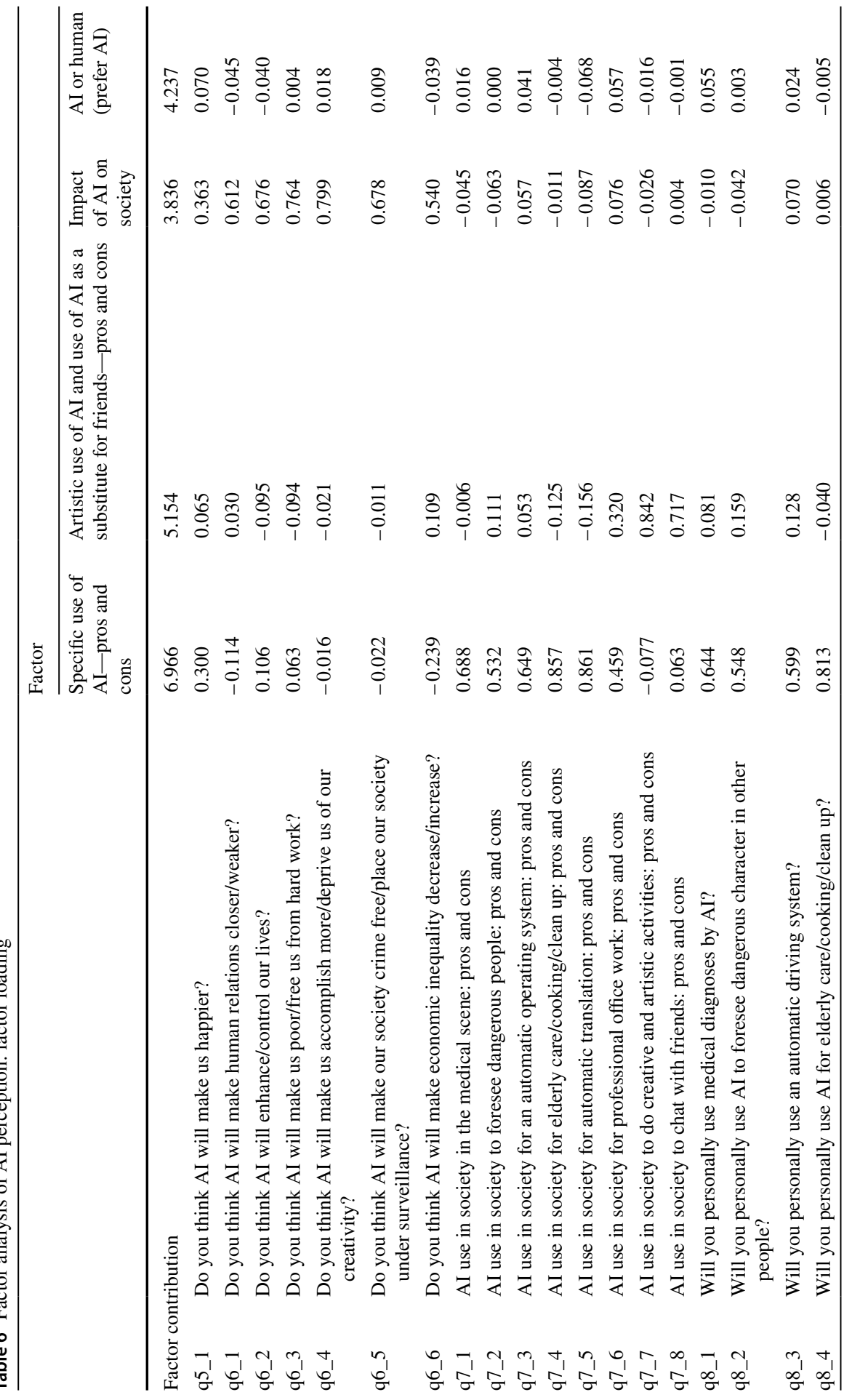




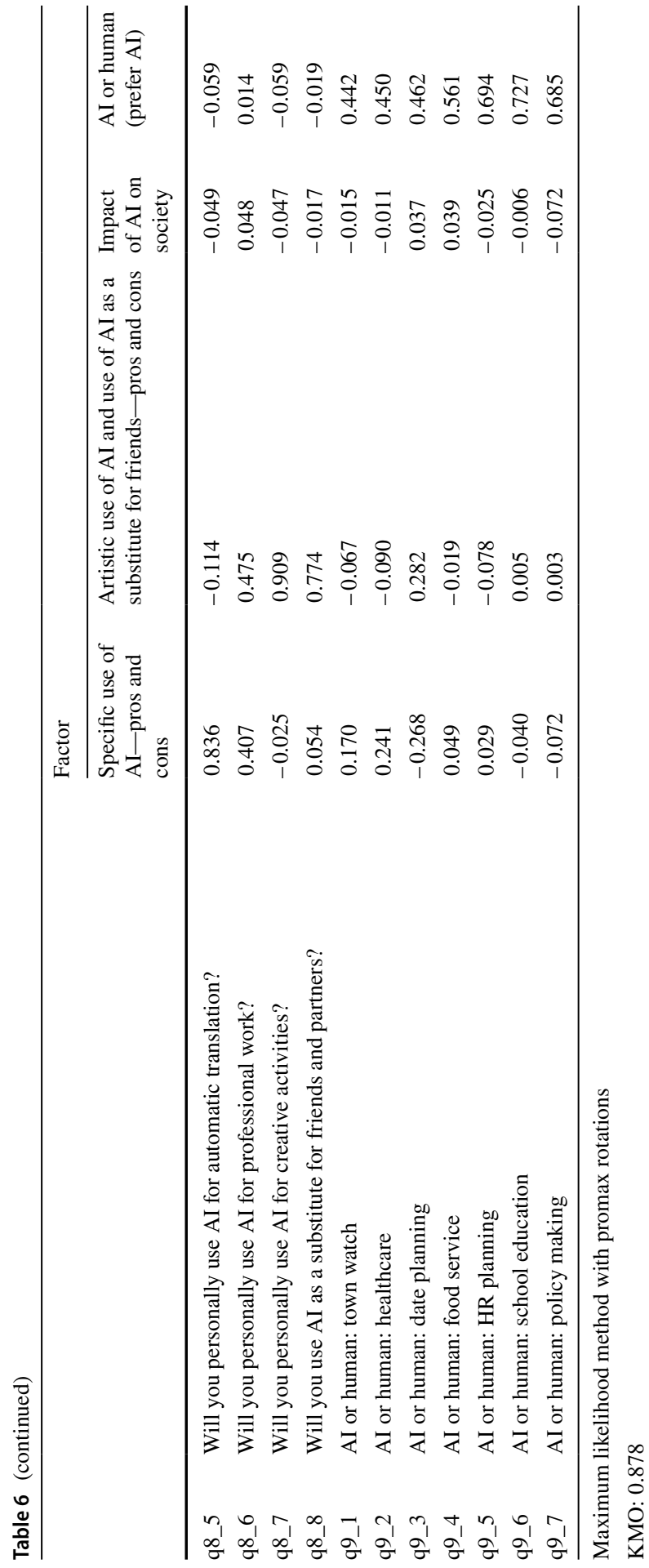


- 7 questions on the respondent's choice between AI or Humans in 7 applications, measured using a four-point Likert scale.

The questions on AI in our survey cover four broad areas that we call AI perception as a whole. There were also questions on the personal characteristics of the respondents including gender, age, educational attainment, marital status, occupation, form of employment (permanent or temporary), family income, number of cohabiting people, time spent in current residence, municipality, and perception of risk. The questionnaire was checked and approved by the Ethical Committee (Social Science) of Tohoku University. ${ }^{3}$ The authors have no competing interests to declare.

\subsection{Methodology}

RS1 We conducted three exploratory factor analyses (EFA) using the abovementioned data on ICT literacy, SC, and perceptions of AI to obtain information on basic factors in each of the three groups of questions.

$R S 2$ Then, using the factor scores obtained from the explanatory analyses, we performed an analysis with SEM to confirm the validity of the factors obtained by the exploratory factor analyses in light of the results of preceding studies. As an extension of the third wave of previous studies that have attempted to explain the impact of SC on ICT, we used SC factors as independent variables and ICT factors as dependent ones.

$R S 3$ We performed another SEM to see the impact of each of the four components of SC obtained from the factor analysis on perceptions of AI.

Besides these SEM analyses, we carried out logistic regressions with dichotomized scores, categorical regressions and OLSs without dichotomizing factor scores (the results not shown in the present paper). We obtained mostly the same tendency as the results of these regressions. We used SPSS ver. 25 with AMOS ver. 26 for all analyses.

\section{Results}

As a result of applying EFAs using the maximum likelihood method with promax rotation, five factors concerning ICT literacy, four concerning SC, and four concerning perceptions of AI were extracted (see Tables 4, 5, and 6). As shown in Tables 4, 5 , and 6, the $\mathrm{KMO}^{4}$ scores for ICT literacy, SC, and perceptions of AI were 0.905 , 0.813 , and 0.878 , respectively. All the factors are with eigenvalues over one except for one SC factor.

\footnotetext{
${ }^{3}$ Approved by the Research Ethics Committee of Tohoku University on July 11, 2018. Approval number: $0711-115252$.

${ }^{4}$ Kaiser-Meyer-Olkin measure of sampling adequacy. The value closer to one means the higher adequacy of the sample.
} 
The five factors related to ICT literacy were labeled "PC and software use capability" (eigenvalue $=7.591, \alpha=0.862$ ), "access to ICT devices and PC" (2.631, $\alpha=0.742$ ), "frequency of information retrieval/exchange" (eigenvalue $=2.278$, $\alpha=0.751$ ), "AI-related device use" (eigenvalue $=1.772, \alpha=0.679$ ), and "software use-word processors and spreadsheets" (eigenvalue $=1.317, \alpha=0.914$ ), as seen in Table 4. Factors with eigenvalues equal to or over one were selected.

As seen in Table 5, we obtained four factors in relation to SC, namely "structural SC group activities" (eigenvalue $=3.895, \alpha=0.694$ ), "cognitive SC" (eigenvalue $=1.894, \alpha=0.830$ ), "structural SC-contacts with others" (eigenvalue $=1.310, \alpha=0.669$ ), and "structural $\mathrm{SC}$ - workplace" (eigenvalue $=0.839$, $\alpha=$ na). Although the eigenvalue of the last SC factor is less than one, the factor accounts for approximately $7 \%$ of the variance. Besides, SC at the workplace is known to be of importance in many empirical studies including one by the author. We decided to include it as an SC factor.

As seen in Table 6, we obtained four factors pertaining to AI perception, namely "AI practical use-pros and cons" (eigenvalue $=8.506, \alpha=0.911$ ), "AI artistic use and as a substitute for friends" (eigenvalue $=3.477, \alpha=0.876$ ), "influence of AI on society" (eigenvalue $=2.595, \alpha=0.803$ ), and "AI or Human" (eigenvalue $=1.922, \alpha=0.778$ ).

The following analyses were carried out using the factor scores obtained from the abovementioned factor analyses. Higher values of AI-related factors indicate affirmative perceptions of AI.

\section{Analysis one Association among SC, ICT literacy, and AI perception}

As an extension of wave three, we assumed SC as an explanatory variable and ICT literacy as a dependent one. Whereas most previous studies are based on a partial picture of ICT such as email exchanges or particular types of SNSs (e.g., Facebook, Line, or RPGs), this study places greater emphasis on comprehensive literacy of ICT such as the capabilities of PC and software use.

As seen in Fig. 1, a confirmatory pass analysis was conducted using all factors on SC, ICT literacy, and AI perception obtained in the exploratory factor analyses to test the validity of the factors in explaining the associations among SC, ICT literacy, and AI perception. The three latent variables (SC, ICT literacy, AI perception) we created do not contradict with the knowledge found by preceding studies, especially those in the wave three mentioned above. That is, SC is positively associated with ICT literacy. It also provided a new finding. ICT literacy is positively associated with AI perception as well. Therefore, SC is indirectly associated with affirmative perceptions of AI.

Analysis two How each component of SC is associated with ICT literacy and AI perception?

We carried out another SEM to find out how each of the four components of SC is associated with ICT literacy and AI perception (Fig. 2).

The findings Fig. 2 suggests are as follows. 


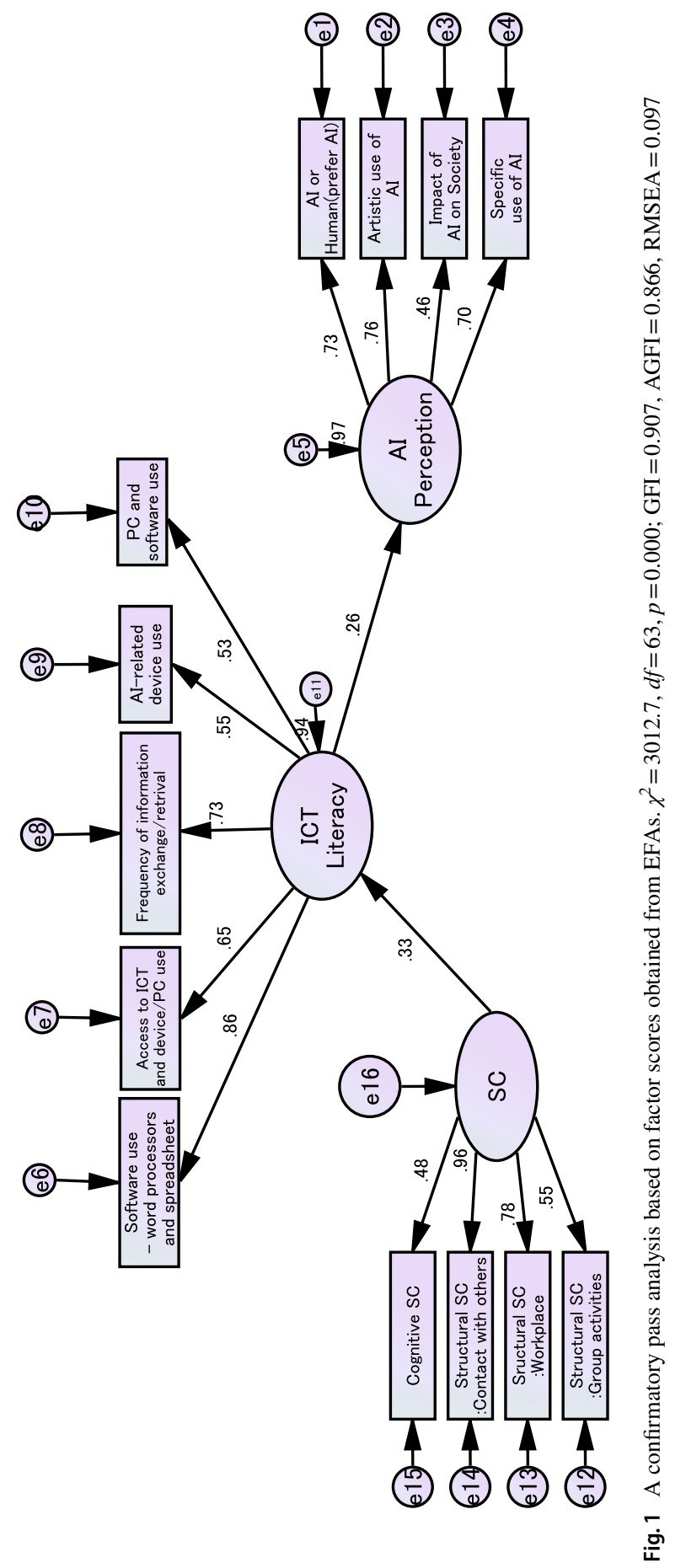




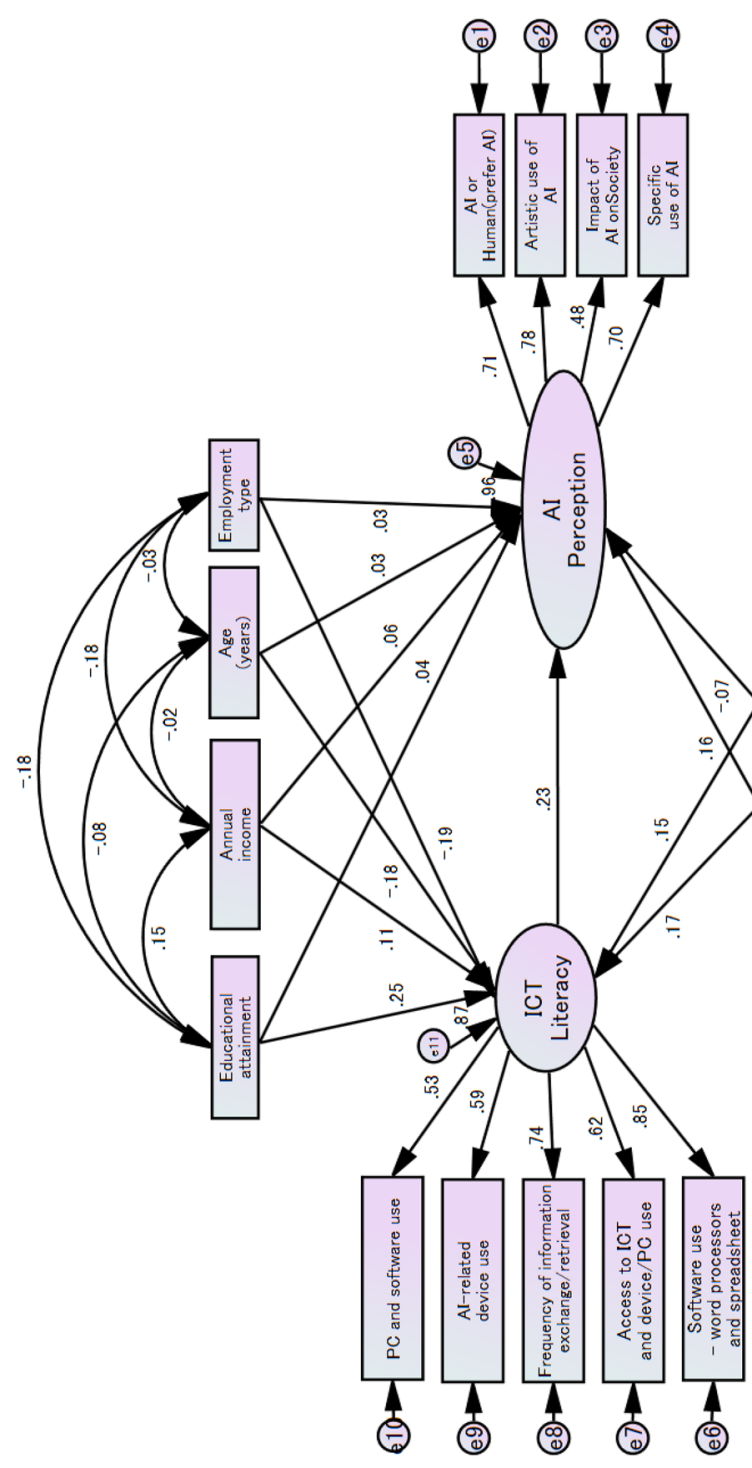

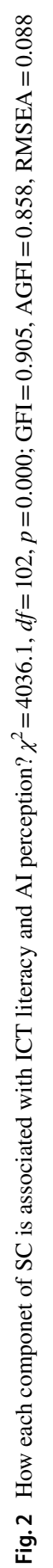


1. With regard to direct association from the SC components to ICT literacy, only two elements of SC, namely "structural SC_-workplace" and "structural SCgroup participation" has statistically significant positive association with ICT literacy. Neither "cognitive SC" nor "structural SC_contact with others" has no association with ICT literacy.

2. Therefore, the indirect pass suggested in Figure one from ICT literacy to AI perception is assumed to be mainly caused by "structural SC-workplace" and "structural SC-group participation".

3. However, the two elements of SC ("cognitive SC" and "structural SC-contact with others") which do not have association with ICT literacy do have direct association with AI perception. One ("cognitive SC") positive, another("structural SC-contact with others") negative.

4. With regard to the attributes of respondents, both education and annual income have positive association with ICT literacy, while age and employment type have negative association with ICT literacy. Those with higher education or income show higher ICT literacy, while those aged or with more unstable jobs tend to have lower ICT literacy.

5. In summary, SC is mainly associated with affirmative perceptions of AI. However, structural SC has an ambivalent effect on AI perception: "contacts with others" represents cautious views on AI, while "group participation" and "workplace" promote affirmative perceptions of AI.

\section{Discussion}

\subsection{Direct impact of SC on Al perception}

We assume that the results of analysis two (Fig. 2) represent the direct impact of SC on AI perception. Those with a higher cognitive SC are affirmative toward AI. On the other hand, "Structural SC: contact with others" has a negative effect toward the use of AI. Although not shown in the paper, when it comes to the preference between AI and humans, those with frequent contact with others prefer humans over AI (a statistically significant negative correlation observed between "structural SC-contacts with others" and "AI perception: AI or Human"). Since "contacts with others" mainly mean daily social contacts with neighbors and with friends and acquaintances in a neighborhood, it may represent homophily or networks among people with the same background. Those with close contacts with others may have difficulties in adopting new "relationship" with AI.

\subsection{Indirect impact of SC on AI perception through ICT literacy}

The results of the two analyses shown in Figs. 1 and 2 combined may suggest the indirect impact of two types of structural SC, "SC-group activities" and "SCworkplace" on AI perception through ICT literacy. ICT provides an interface between $\mathrm{AI}$ and humans, and thus, it functions as an intermediary between SC and 
AI perception. From that perspective, the strong association between structural SC and ICT literacy shown in Fig. 1 as well as the association between ICT literacy and the specific types of SC (Fig. 2) suggests the existence of an indirect pass between structural SC and AI perception. In other words, activities in various networks such as group activities and those at workplace enhance ICT literacy and, in turn, lead to affirmative perceptions of practical use of AI. The network made at workplace and by group participation may be less homophilic than networks of neighbors. In fact, they may represent networks' heterophily (Rogers 1962). The former enhances networks among those that have similar backgrounds, whereas the later fosters networks between those with different backgrounds. The results of Figs. 1 and 2 suggest heterophily embedded in networks may work for the affirmative perceptions of AI through ICT literacy.

\section{Limitations}

This study has a number of limitations. First, the samples used are biased. The data were collected online based on the registry of a web-survey firm. A total of 5000 answers were collected, comprising 1000 answers from each of the 10-year age groups from 20 to 69 years. The average age of the sample (44.8 years) was younger than that of the entire Japanese population at of the end of October 2017 $\left(47.4\right.$ years $\left.^{5}\right)$. Virtually, all respondents were capable of using the Internet and, thus, their ICT literacy was assumed to be higher than that of the average Japanese population. Second, we cannot specify any causality based on the cross-sectional data used in this study except for causality from SC/ICT literacy to AI perception. Longitudinal data are required to identify causality. Third, the scope of our study is limited to SC at the individual level. No contextual SC or community SC is examined. Fourth, SEMs utilized in Figs. 1 and 2 leave somewhat to be desired in terms of both the GFI and $\chi^{2}$ test. Fifth, it did not mention the theoretical mechanisms that clarify the causalities among SC, ICT literacy, and AI perception. Finally, this paper did not directly address the ultimate research question on how AI will affect SC in the future.

\section{Conclusion}

We found a statistically significant positive association between $\mathrm{SC}$ and positive perceptions of AI through ITC literacy. SC is indirectly associated with AI perception by enhancing ICT literacy, and then ICT literacy enhances AI perception. This indirect effect seems to be mainly caused by two types of structural SC: SC through group participations and SC at work place.

\footnotetext{
5 The Japanese population as of October 1, 2019, based on a Census by the Statistics Bureau of Japan. https://www.stat.go.jp/data/nihon/02.html accessed on August 25, 2019.
} 
Besides this indirect effect, SC has direct effect on AI perception. Cognitive SC has direct positive association with AI perception, whereas structural SC in the form of contacts with others was negatively associated with AI perception.

Thus, structural SC has an ambivalent effect on AI perception. Structural SC through group participation as well as SC at work place may work for the positive perceptions of AI through ICT literacy, while those with higher level of contacts with others tend to be cautious toward AI.

Both cognitive SC and structural SC assume important roles for the smooth transition into the AI era. Policy makers should be aware of the difference in the way each of these SC forms affects AI perception. SC seems to have mainly promotional impact on the AI perception. However, the precautionary function of SC should not be put on the back burner for the sound social acceptance of AI. In any case, SC assumes an important role in the creation of AI perception.

Acknowledgements The survey on which this study is based was conducted with financial support from the Japanese Society for the Promotion of Science (JSPS) Grant-in-Aid for Challenging Research (KAITAKU) (Grant No. 17H06195). Authors are grateful for this support.

Open Access This article is licensed under a Creative Commons Attribution 4.0 International License, which permits use, sharing, adaptation, distribution and reproduction in any medium or format, as long as you give appropriate credit to the original author(s) and the source, provide a link to the Creative Commons licence, and indicate if changes were made. The images or other third party material in this article are included in the article's Creative Commons licence, unless indicated otherwise in a credit line to the material. If material is not included in the article's Creative Commons licence and your intended use is not permitted by statutory regulation or exceeds the permitted use, you will need to obtain permission directly from the copyright holder. To view a copy of this licence, visit http://creativecommons.org/licen ses/by/4.0/.

\section{References}

Ahmed Z (2018) Explaining the unpredictability: a social capital perspective on ICT intervention. Int J Inf Manage 38(1):175-186

Bauernschuster S, Falck O, Woessmann L (2014) Surfing alone? The internet and social capital: evidence from an unforeseeable technological mistake. J Public Econ 117:73-89

Bourdieu P (1986) The forms of capital. In: Richardson JG (ed) Handbook of theory and research for the sociology of education. Greenwood Public Group, Westport conn. pp 46-58 Reproduced (2006) In: Lauder H, Blown P, Dillabough J, Halsey AH (eds) Education, globalization and social capital. Oxford University Press, New York, pp 105-118

Bowls S, Gintis H (2002) Social capital and community governance. Econ J 112(483):F419-F436

Burt SR (1992) Structural Holes: the social structure of competition. Harvard University Press, Massachusetts

Campbell SW, Kwak N (2012) Mobile communication and strong network ties: shrinking or expanding spheres of public discourse? New Media Soc 14(2):262-280

Coleman JS (1987) Norms as Social Capital. In: Radnitzky G, Bernholz P (eds) Economic imperialism: the economic approach applied outside the field of economics. Paragon House Publishers, St. Pail, pp 133-155

Coleman JS (1988) Social capital in the creation of human capital. Am J Soc 94:95-120

Ellison NB, Steinfield C, Lampe C (2007) The Benefits of facebook "friends:" social capital and college students' use of online social network sites. J Comput-Mediat Commun 12(4):1143-1168 
Gergen KJ (2008) Mobile communication and the transformation of the democratic process. In: Katz J (ed) Handbook of mobile communication studies. MIT Press, Cambridge, pp 297-310

Habuchi I (2005) Accelerating reflexivity. In: Ito M, Okabe D, Matsuda M (eds) Personal, portable, pedestrian: mobile phones in Japanese life. MIT Press, Cambridge, pp 165-182

Inaba Y (2005) Economic implications of social capital: How should we deal with externalities through our minds? Plan Adm 28(4):17-22 (in Japanese)

Inaba Y, Yoshino R (2016) The world of social capital-its academic effectiveness, policy implications, and analytical method series social capital, vol 1. Minerva Shobo, Kyoto (in Japanese)

Ishizuka M et al (2017) Introduction. In: The Japan Society for Artificial Intelligence (ed) Encyclopedia of artificial intelligence. Kyoritsu Shuppan, Tokyo, pp 2-4 (in Japanese)

Kim Y, Hsu SH, de Zúñiga HG (2013) Influence of social media use on discussion network heterogeneity and civic engagement: the moderating role of personality traits. J Commun 63(3):498-516

Kobayashi T, Boase J (2014) Tele-Cocooning: mobile texting and social scope. J Comput-Mediat Commun 19(3):681-694

Kobayashi T, Ikeda K (2006) The development of social capital in communities in an online game: a perspective on a "spill over" effect into the offline world. Jpn J Soc Psychol 22(1):58-71 (in Japanese)

Kuo FY, Tseng FC, Lin CIC, Tang WH (2013) Critical success factors for motivating and sustaining women's ICT learning. Comput Educ 67:208-218

Li X, Chen W (2014) Facebook or Renren? A comparative study of social networking site use and social capital among Chinese international students in the United States. Comput Hum Behav 35:116-123

Lin N (2001) Social capital: a theory of social structure and action. Cambridge University Press, Cambridge

Ling R (2008) New tech, new ties: How mobile communication is reshaping social cohesion. MIT Press, Cambridge

Lu J, Yang J, Yu C (2013) Is social capital effective for online learning? Inf Manag 50(7):507-522

Miyata K (2005a) Social psychology of the internet: the function of the internet from a viewpoint of social capital. Kazama Shobo, Tokyo (in Japanese)

Miyata K (2005b) Media as a bridge among human ties: social capital in the era of the internet. NTT Publishing, Tokyo (in Japanese)

Miyata K (2005c) The mobile-izing Japanese: connecting to the Internet by PC and Webphone in Yamanashi. In: Ito M, Okabe D, Matsuda M (eds) Personal, portable, pedestrian: mobile phones in Japanese life. MIT Press, Cambridge, pp 143-164

Miyata K, Wellman B, Boase J (2005) The wired- and Wireless- Japanese: webphones, PCs and social networks. In: Ling R, Pedersen PE (eds) Mobile communications: re-negotiation of social sphere. Springer, New York, pp 427-449

Naranjo-Zolotov M, Oliviera T, Frederico CJ, Martins J, Gonçalves R, Branco F, Xavier N (2019) Examining social capital and individual motivators to explain the adoption of online citizen participation. Future Gener Comput Syst 92:302-311

Nie NH, Erbring L (2002) Internet and society: preliminary report. IT Soc 1(1):275-283

Nolan S, Hendricks J, Towell A (2015) Social networking sites (SNS); exploring their uses and associated value for adolescent mothers in Western Australia in terms of social support provision and building social capital. Midwifery 31(9):912-919

Norris P (2003) Social capital and ICTs: widening or reinforcing social networks? Paper presented at the International Forum on Social Capital for Economic Revival held by the Economic and Social Research Institute, Cabinet Office, Japan in Tokyo, 24-25 March 2003

OECD (2001) The well-being of nations: the role of human and social capital. OECD Publishing, Paris

Ostrom E (1999) Social capital: a fad or a fundamental concept? In: Dasgupta P, Serageldin I (eds) Social capital a multifaceted perspective. The World Bank, Washington

Ostrom E, Ahn TK (2009) The meaning of social capital and its link to collective action. In: Gert Tinggaard Svendsen, Gunnar Lind Haase Svendsen (eds) Handbook of social capital: the troika of sociology, political science and economics. Edward Elgar, Cheltenham, pp 17-35

Penard T, Poussing N (2010) Internet use and social capital; the strength of virtual ties. J Econ Issues 44(3):569-595

Putnam RD (1993) Making democracy work: civic traditions in modern Italy. Princeton University Press, New Jersey

Putnam RD (2000) Bowling alone. Touchstone, New York

Rogers E (1962) Diffusion of innovations. Free Press, New York 
Ryan S (2010) Information systems and healthcare XXXVI: building and maintaining social capital-evidence from the field. Commun Assoc Inf Syst 27(18):307-322

Salahuddin M, Tisdell C, Burton L, Alam K (2016) Does internet stimulate the accumulation of social capital? A macro-perspective from Australia. Econ Anal Policy 49:43-55

Suda K (2018) Social media as a base of our society. In: Omori T (ed) Social capital and economics. Minerva Shobo, Kyoto, pp 110-134 (in Japanese)

Terashima K, Miura A (2013) Does use of SNS develop offline/online social capital? Kwansei Gakuin Univ Bull Psychol Sci 39:59-67 (in Japanese)

Tsuji I (2014) Can mobile medias be social capital? In: Matsuda M, Dobashi S, Tsuji I (eds) The 2000s of mobil media-matured mobile society. Tokyo University Press, Tokyo, pp 225-254 (in Japanese)

Wellman B, Quan Haase A, Witte J, Hampton K (2001) Does the internet increase, decrease, or supplement social capital? Am Behav Sci 45(3):436-455

Woolcock M (1998) Social Capital and economic development: toward a theoretical synthesis and policy framework. In: Ostrom E, Ahn TK (eds) (2003) foundations of social capital. Edward Elgar, Cheltenham, pp 343-400

Yang S, Lee H, Kurnia S (2009) Social capital in information and communications technology research: past, present, and future. Commun Assoc Inf Syst 25(23):183-220. https://doi.org/10.17705/1CAIS .02523

Zhong ZJ (2014) Civic engagement among educated Chinese youth: the role of SNS (social networking services) bonding and bridging social capital. Comput Educ 75:263-273

Publisher's Note Springer Nature remains neutral with regard to jurisdictional claims in published maps and institutional affiliations.

\section{Affiliations}

\section{Yoji Inaba $^{1}$ [D $\cdot$ Kazunari Togawa ${ }^{2}$}

Yoji Inaba

Inaba.yoji@nihon-u.ac.jp

Kazunari Togawa

Togawa.kazunari.xa@alumni.tukuba.ac.jp

1 College of Law, Nihon University, 2-3-1 Kanda-Misakicho, Chiyoda-ku, Tokyo, Japan

2 University of Tsukuba, 1-16-7 Ryougoku, Sumida-ku, Tokyo, Japan 